\title{
Chemical Reactivity Indices of the Caffeine Molecule
}

\author{
de Almeida, A. L.; Barbosa, L. P. G.; Santos, R. L.; Martins, J. B. L.* \\ Rev. Virtual Quim., 2016, 8 (2), 483-492. Data de publicação na Web: 8 de abril de 2016 \\ http://rvq.sbq.org.br
}

\section{Índices de Reatividade da Molécula de Cafeína}

Resumo: Apresentamos neste trabalho uma análise da molécula de cafeína usando funções de base difusas e polarizadas, $6-31++G(d, p)$ e aug-cc-pVDZ, assim como a função de base D95V, combinadas com os métodos HF, MP2 e DFT. O objetivo foi investigar os efeitos destes métodos e funções de base nos descritores químicoquânticos, potencial de ionização, afinidade eletrônica, dureza química, potencial químico e filicidade global da molécula de cafeína, $\mathrm{C}_{8} \mathrm{H}_{10} \mathrm{~N}_{4} \mathrm{O}_{2}$. A análise de componentes principais foi realizada para correlacionar os resultados. Também realizamos análise de cargas atômicas calculadas com os métodos de Mulliken, MerzKollman e orbitais atômicos naturais.

Palavras-chave: NBO; reatividade química; MP2; DFT.

\begin{abstract}
In this paper we present an analysis of the caffeine molecule using diffuse and polarized basis functions, $6-31++G(d, p)$ and aug-cc-pVDZ, as well as theD95V basis set, combined with the HF, MP2 and DFT methods. The aim was to investigate the effects of these methods and basis sets in quantum chemical descriptors, e.g., ionization potential, electron affinity, chemical hardness, chemical potential and global philicity index of the caffeine molecule, $\mathrm{C}_{8} \mathrm{H}_{10} \mathrm{~N}_{4} \mathrm{O}_{2}$. A principal component analysis was performed to correlate the results. We have also carried out population analysis of atomic charges with Mulliken, Merz-Kollman and Natural Atomic Orbital methods.
\end{abstract}

Keywords: NBO; chemical reactivity; MP2; DFT.

\footnotetext{
* Universidade de Brasília, Instituto de Química, Laboratório de Química Computacional, CP 4478, CEP 70904-970, Brasília-DF, Brasil.

Mlopes@unb.br

DOI: $\underline{10.5935 / 1984-6835.20160035}$
} 


\title{
Chemical Reactivity Indices of the Caffeine Molecule
}

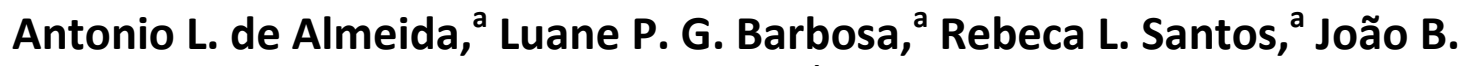 \\ L. Martins ${ }^{\mathrm{b}, *}$ \\ a Universidade do Estado da Bahia, Departamento de Ciências Exatas e da Terra, Rua Silveira \\ Martins, 2555, CEP 41150-00, Cabula, Salvador-BA, Brasil.

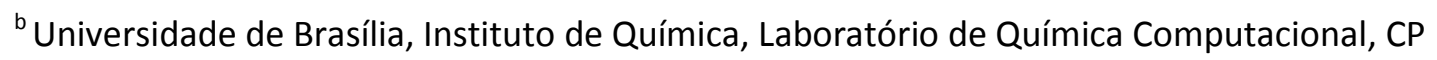 \\ 4478, CEP 70904-970, Brasília-DF, Brasil. \\ *lopes@unb.br
}

\section{Introduction}

\section{Computational Details}

\section{Results}

\section{Conclusions}

\section{Introduction}

Quantum chemistry methods are of particular importance to understand stability and reactivity of target molecules. ${ }^{1}$ In this sense, quantum chemical descriptors take advantage of structure and properties relationship to estimate and determine the reactivity. Global reactivity indexes have been widely used to study molecules and reactions, ${ }^{1-5}$ and have been effectively handled by the conceptual density functional theory (DFT) ${ }^{5,6}$

The caffeine molecule $\left(\mathrm{C}_{8} \mathrm{H}_{10} \mathrm{~N}_{4} \mathrm{O}_{2}\right.$, Figure 1 ) is known as a psychoactive stimulant, and it is included in the xanthine molecule class. This molecule show many important biological and pharmacological activities, which was the point of interest for several theoretical studies, using DFT, Hartree-Fock (HF) and second-order perturbation theory
(MP2) to analyze its vibrational spectrum, molecular structure, electronic excitation energies, density maps, and NMR. ${ }^{7-12}$

We investigated the effects of several methods and basis set in quantum chemical descriptors, i.e., ionization potential, electron affinity, chemical hardness, chemical potential and global philicity index for the caffeine molecule, $\mathrm{C}_{8} \mathrm{H}_{10} \mathrm{~N}_{4} \mathrm{O}_{2}$. Principal component analysis (PCA) was used to correlate the descriptors used in this work. The analysis of atomic charges distribution was investigated with Mulliken, ${ }^{13}$ MerzKollman $^{14}$ and Natural Bond Orbitals (NBO) ${ }^{15}$ methods.

\section{Computational Details}

In quantum chemistry, the most important in the analysis of results is the 
theory level, defined in terms of calculation procedures from the combination of methods and basis set. We intend to analyze the influence of methods and basis functions in the results obtained for the caffeine molecule. The following basis sets were used: (I) D95; (II) 6-31++G(d,p); (III) aug-cc-pVDZ. As the basis set requirements are different for density functional theory (DFT) ${ }^{16}$ and wave function theory (WFT), we made calculation with both. For density functionals we consider the widely used B3LYP, i.e., combination of the $\operatorname{LYP}^{17,18}$ correlation functional with the Becke three-parameter $(B 3)^{19}$, and LC-WPBE, ${ }^{20-22}$ i.e., long-rangecorrected $\mathrm{WPBE}^{23-25}$, where $\mathrm{w}$ is a parameter defining the range separation, and $P B E$ is an acronyms of Perdew-Burke-Ernzerhof. ${ }^{26}$ B3LYP functional is known to have poor quality for long-distance interactions. LCWPBE, unlike B3LYP, satisfactorily incorporates corrections for long-distance interactions, and correctly predicts the degree of localization and delocalization of electrons. ${ }^{20-25}$ For WFT, we consider HF and MP2. The calculations were performed with the Gaussian09 program, ${ }^{27}$ while Gaussview4.1 was used for the geometry visualization. ${ }^{28}$

HOMO (Highest Occupies Molecular Orbital) and LUMO (Lowest Unoccupied Molecular Orbital) frontier orbitals are the main orbitals that take part in chemical reactivity. The related eigenvalues and their energy gap reflect the chemical activity of the molecule. ${ }^{29,30}$
An approximation for absolute hardness (n) is $\eta=1 / 2(I E-E A), \eta=1 / 2(\mathrm{I}-\mathrm{A})$ where $I E$ is the ionization energy and $E A$ is the electron affinity. ${ }^{31}$ According to the Koopman's theorem we have $\mathrm{I}=-\mathrm{E}(\mathrm{HOMO})$ $I E=-E_{\text {номо }} \quad$ and $\quad E A=-E_{L U M O}$ , $\mathrm{A}=-\mathrm{E}(\mathrm{LUMO})$ where $E_{\text {номо }}$ is the energy of the highest occupied molecular orbital, and $E_{\text {LUMO }}$ is the energy of the lowest unoccupied molecular orbital. The higher HOMO energy indicates the more reactive molecule in reaction with electrophiles. For molecular reaction with nucleophiles, lower LUMO energy is essential. ${ }^{6}$ The $E A$ and $E I$ descriptors are used to yield another global reactivity descriptor, the electronic chemical potential ( $\mu$ ), defined as $\mu=1 / 2(I E-E A) \mu=1 / 2(\mathrm{I}+$ A). ${ }^{32-34}$ In addition, the global philicity index $(\omega)$ is calculated using the electronic chemical potential and chemical hardness $(\eta)$ as $\omega=\mu^{2} / 2 \eta \omega=\mu^{2} / 2 \eta$.

The concept of molecular hardness is related to the stability of the molecular system, according to the principle of maximum hardness formulated by Parr and Pearson. ${ }^{31}$ a direct relationship between the concept of molecular hardness and the aromaticity has been suggested. The energy difference between the HOMO and LUMO frontier orbitals ( $\left.E_{\text {LUмо }}-E_{\text {Hомо }}\right), G A P$, has been used as a quantum chemical descriptor. Small GAP values have been associated with antiaromaticity. ${ }^{35}$ Moreover, the energy GAP also provides valuable information about the thermodynamic stability. 


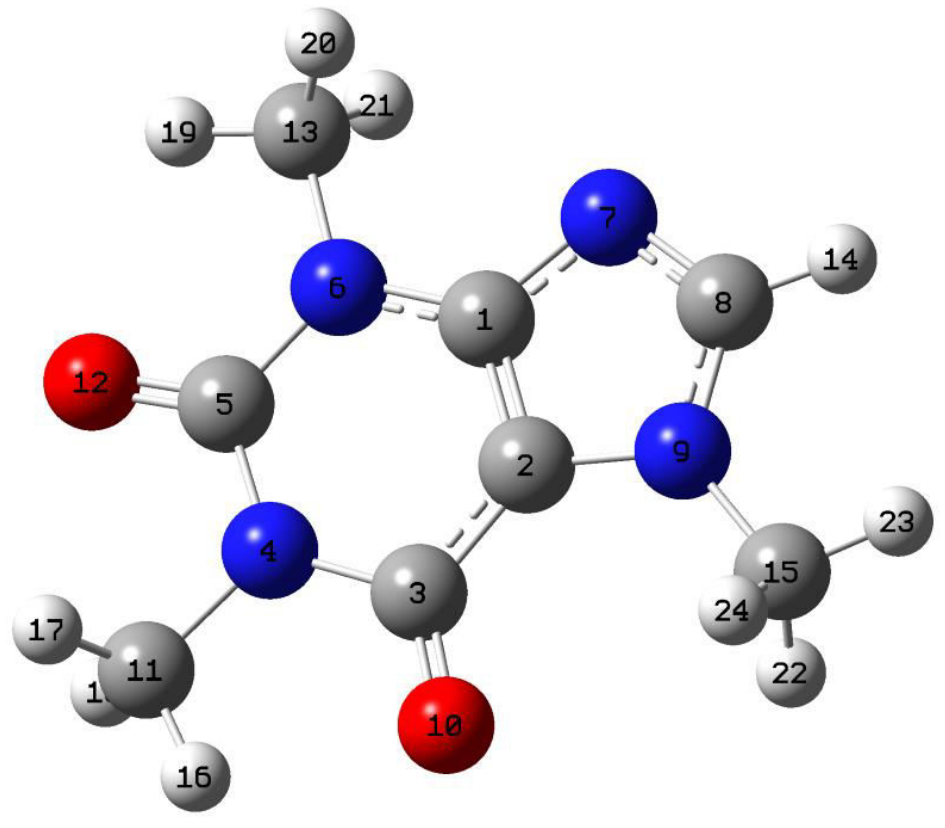

Figure 1. Optimized structure of caffeine molecule at $B 3 L Y P / 6-31++G(d, p)$ level

\section{Results}

Table 1 shows the results for the fulloptimized geometry of the caffeine molecule. These results show that regardless the method, D95V basis set provides the most negative value for HOMO, followed by 6$31++G(d, p)$ and aug-cc-pVDZ. HF and DFT/LC-
WPBE methods provide similar values for the HOMO energy, while DFT/B3LYP provides more pronounced differences than the other methods. The B3LYP method has the lowest negative values for LUMO and the lowest values for the GAP. These B3LYP results suggest higher reactivity in reaction with electrophiles. Therefore, B3LYP functional is overestimating the caffeine reactivity.

Table 1. HOMO, LUMO and GAP values (a.u.) for the caffeine molecule

\begin{tabular}{ccccc}
\hline & Method/Basis Sets & HOMO & LUMO & GAP \\
\hline $\mathbf{1}$ & HF/D95V & -0.333 & 0.087 & 0.420 \\
$\mathbf{2}$ & HF/6-31++G(d,p) & -0.322 & 0.031 & 0.353 \\
$\mathbf{3}$ & HF/aug-cc-pVDZ & -0.320 & 0.025 & 0.345 \\
$\mathbf{4}$ & B3LYP/D95V & -0.234 & -0.054 & 0.181 \\
$\mathbf{5}$ & B3LYP/6-31++G(d,p) & -0.232 & -0.047 & 0.185 \\
$\mathbf{6}$ & B3LYP/aug-cc-pVDZ & -0.232 & -0.048 & 0.183 \\
$\mathbf{7}$ & LC-wPBE/D95V & -0.332 & 0.032 & 0.364 \\
$\mathbf{8}$ & LC-wPBE/6-31++G(d,p) & -0.329 & 0.029 & 0.358 \\
$\mathbf{9}$ & LC-wPBE/aug-cc-pVDZ & -0.327 & 0.024 & 0.352 \\
$\mathbf{1 0}$ & MP2/D95V & -0.330 & 0.071 & 0.401 \\
$\mathbf{1 1}$ & MP2/6-31++G(d,p) & -0.320 & 0.031 & 0.351 \\
$\mathbf{1 2}$ & MP2/aug-cc-pVDZ & -0.317 & 0.025 & 0.342 \\
\hline
\end{tabular}


The molecular hardness is associated to the resistance to change in the electron distribution in the molecule. The calculated results for different methods and basis sets for the chemical descriptors of the caffeine molecule are shown in Table 2. B3LYP values are in contrast to the results obtained with other methods. The lower values for the ionization energy are obtained with the B3LYP method. The B3LYP functional is the only one that shows positive results for the electron affinity. It is well known that LUMO orbital values have little correspondence to the electron affinity from the Koopman theorem, ${ }^{36}$ due to the large self-interaction errors. ${ }^{37}$ Furthermore, the HOMO energies for anions computed by various functionals are positive, indicating that these anions would be unstable toward electron detachment. ${ }^{33,38}$

Table 2. Molecular descriptors (a.u.) for the caffeine molecule

\begin{tabular}{ccccccc}
\hline & Method/Basis Sets & $I$ & $A$ & $\eta$ & $\mu$ & $\omega$ \\
\hline $\mathbf{1}$ & HF/D95V & 0.333 & -0.087 & 0.210 & 0.123 & 0.036 \\
$\mathbf{2}$ & HF/6-31++G(d,p) & 0.322 & -0.031 & 0.177 & 0.145 & 0.060 \\
$\mathbf{3}$ & HF/aug-cc-pVDZ & 0.320 & -0.025 & 0.173 & 0.147 & 0.063 \\
$\mathbf{4}$ & B3LYP/D95V & 0.234 & 0.054 & 0.090 & 0.144 & 0.115 \\
$\mathbf{5}$ & B3LYP/6-31++G(d,p) & 0.232 & 0.047 & 0.092 & 0.140 & 0.106 \\
$\mathbf{6}$ & B3LYP/aug-cc-pVDZ & 0.232 & 0.048 & 0.092 & 0.140 & 0.107 \\
$\mathbf{7}$ & LC-wPBE/D95V & 0.332 & -0.032 & 0.182 & 0.150 & 0.062 \\
$\mathbf{8}$ & LC-wPBE/6-31++G(d,p) & 0.329 & -0.029 & 0.179 & 0.150 & 0.090 \\
$\mathbf{9}$ & LC-wPBE/aug-cc-pVDZ & 0.327 & -0.024 & 0.176 & 0.076 & 0.016 \\
$\mathbf{1 0}$ & MP2/D95V & 0.330 & -0.071 & 0.201 & 0.130 & 0.042 \\
$\mathbf{1 1}$ & MP2/6-31++G(d,p) & 0.320 & -0.031 & 0.176 & 0.145 & 0.060 \\
$\mathbf{1 2}$ & MP2/aug-cc-pVDZ & 0.317 & -0.025 & 0.171 & 0.171 & 0.085 \\
\hline
\end{tabular}

Figure 2 shows the principal component analysis using the following descriptors: ionization energy, electron affinity, chemical hardness, chemical potential, global philicity index and GAP. PC1 is dominated by ionization energy, electron affinity, chemical hardness, global philicity index and GAP. Otherwise, PC2 is dominated by chemical potential. DFT methods are clustered together, separated from MP2 and HF. D95V at MP2 and HF level is also separated from the entire set, while for DFT it is only slightly separated from the other basis sets. MP2 and $\mathrm{HF}$ are clustered when using the 6-
$31++G(d, p)$ and aug-cc-pVDZ basis sets. Therefore, PCA results suggest that LC-wPBE, $\mathrm{HF}$ and MP2 using the larger basis sets give almost the same trend for the computed descriptors. This is in accordance to the overestimation of reactivity found from the B3LYP GAP values. According to these results the LC-wPBE functional shows reliable results compared to the perturbation theory with gain in computational effort. Moreover, small basis set does not guarantee reasonable accordance with high level methods and basis sets. 


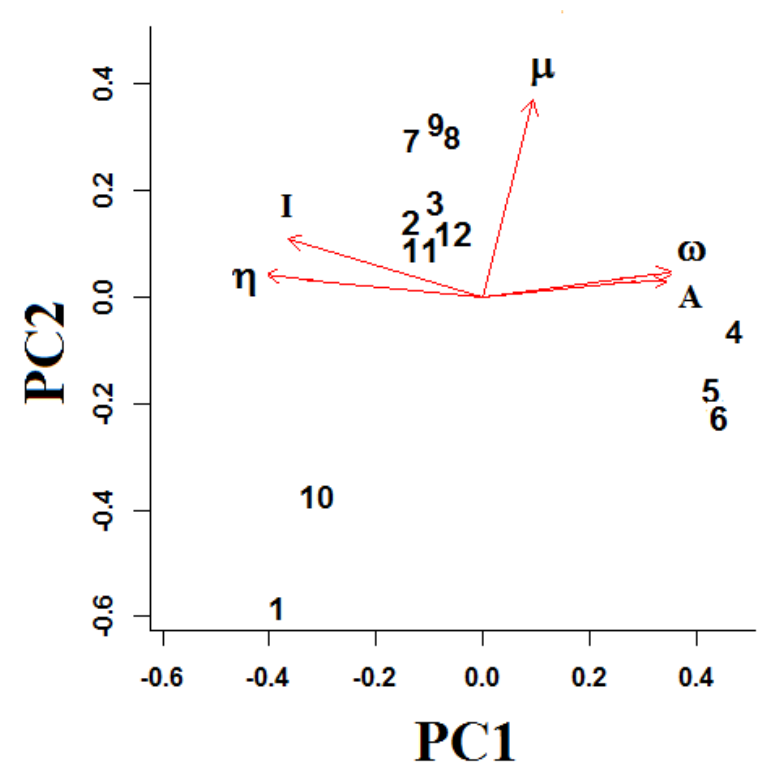

Figure 2. Principal component scores, using ionization energy, electron affinity, chemical hardness, chemical potential, global philicity index, and GAP. See Table 1 for the number notation

Analysis of the distribution of charges could help understand the reactivity of atomic sites in a molecule (local reactivity). Although atomic charge is not a quantum chemistry observable, atomic charges are a useful concept for understanding chemical reactivity. It is of fundamental importance for the understanding of a range of phenomena, e.g., dipole moments and chemical shifts in nuclear magnetic resonance (NMR). Because of its importance, a large number of theoretical and experimental contributions have been proposed $^{39}$ for computation of atomic charge distribution in molecules.

Mulliken analysis has the advantage of simplicity, because its population overlap is divided equally between the two atoms of a bond. However, it reveals a number of results that come at odds with expectations..$^{39-40}$ In general natural atomic charges is fairly independent of the method used in their computation wave functions used. ${ }^{40}$ Figure 3 depicts Mulliken, Merz-Kollman and NBO population charges. As expected Mulliken charges are strongly dependent on the basis set, but shows no dependence on the method used. Merz-Kollman and NBO atomic charges show almost the same trend. The well known behavior of natural analysis is reproduced. NBO has the fairly independent distribution on method and basis set. The Merz-Kollman method shows a disagreement in relation to the $\mathrm{N} 9$ positive results, in this case N7 continues to have smallest charge value in relation to N9. Therefore, NBO results showed to be more independent in the charge distribution, and it should be widely used to rationalize the chemical reactivity. 

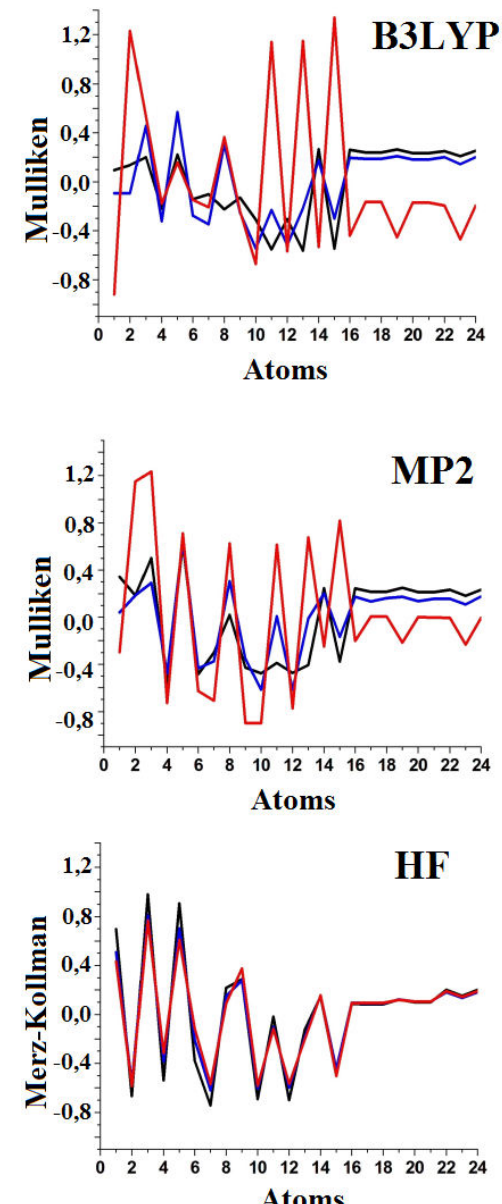

Atoms

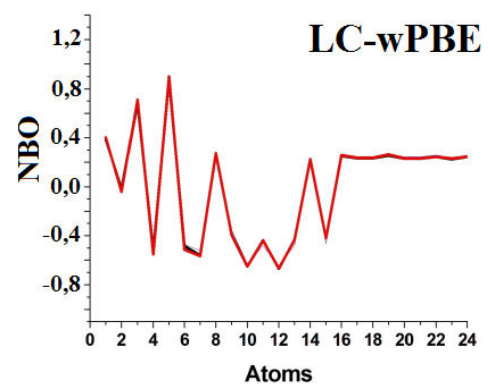

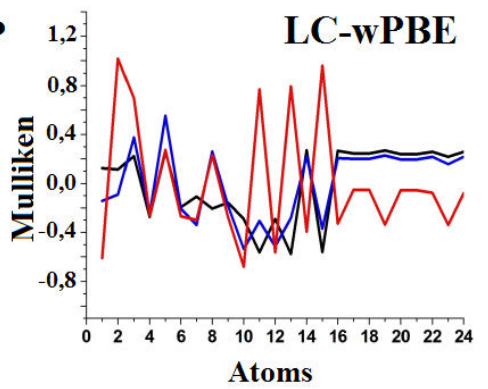

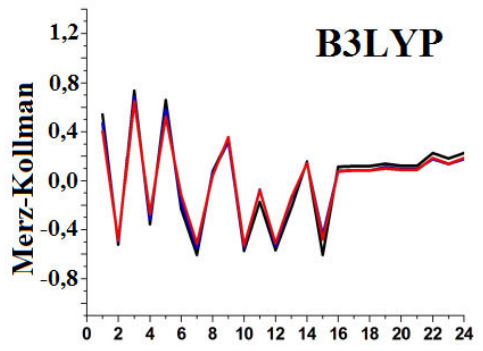

Atoms
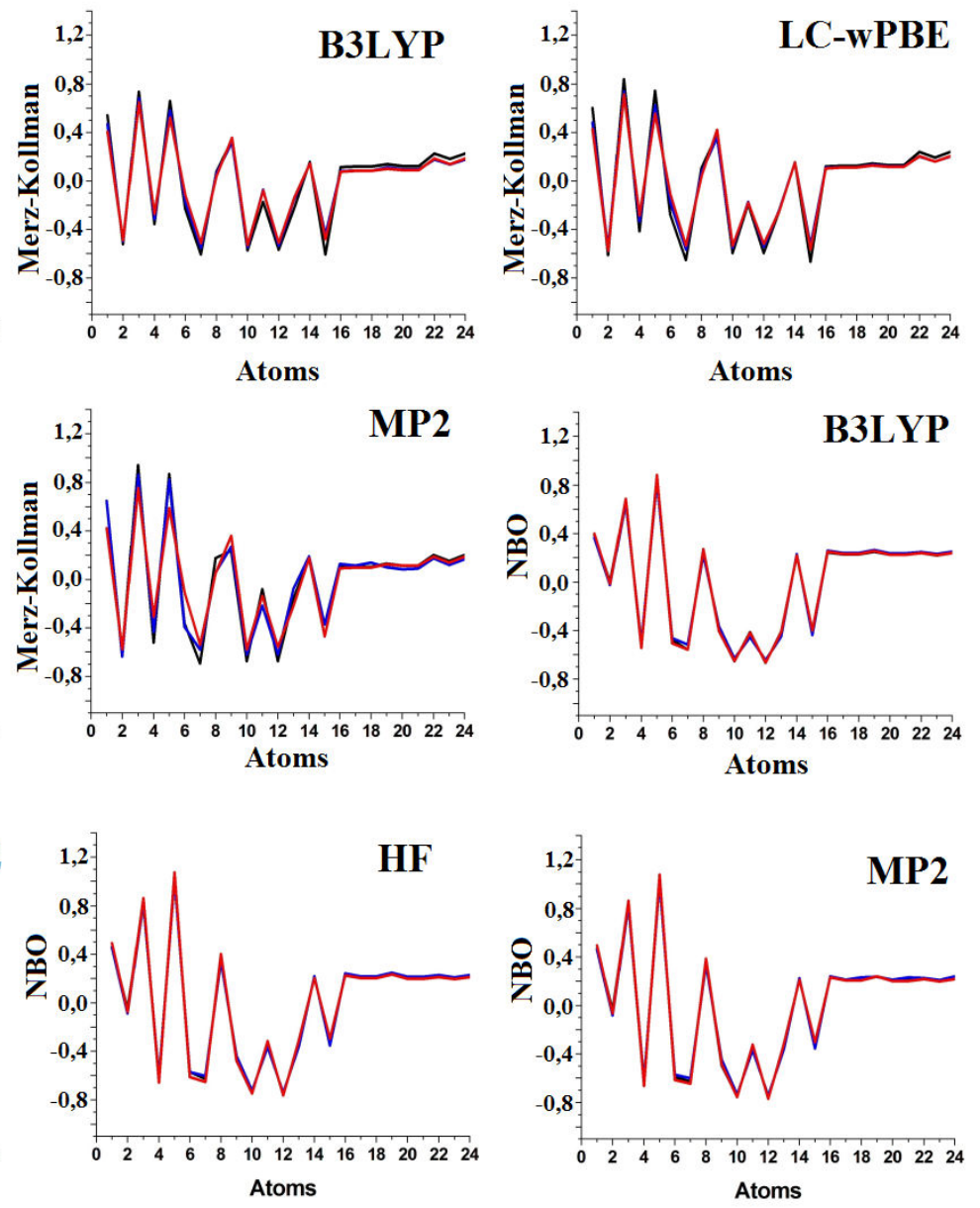

Figure 3. B3LYP, LC-WPBE, HF and MP2 results for the atomic charge populations. Black lines are for $D 95$, blue lines are $6-31++G(d, p)$ and red lines are for aug-cc-pVDZ basis sets. See Figure 2 for the atom notation used

\section{Conclusions}

We have carried out HF, DFT (LC-wPBE and B3LYP) and MP2 calculations of quantum chemical descriptors for the caffeine molecule. The D95V, 6-31++G(d,p) and augcc-pVDZ basis sets were used. The calculated chemical descriptors are ionization energy, electron affinity, chemical hardness, global philicity index, chemical potential and GAP. The results presented in this paper reveal that a careful choice of methods and basis sets is of fundamental importance to yield accurate quantum chemical descriptors. PCA results helps to correlate method and basis set with low computational resource to give the best estimation of these descriptors. Using LC-wPBE and $6-31++G(d, p)$ or aug-ccpVDZ basis sets in combination with NBO 
charge distribution provides reliable quantum chemical descriptors, with results in accordance to those obtained with perturbation theory.

\section{Acknowledgements}

The authors thank the Department of Exact and Earth Sciences (DCETI-UNEB), CNPq, FINATEC, FAPEG and CAPES for financial support. The authors gratefully acknowledge the constructive comments on the paper made by the referee.

\section{References}

${ }^{1}$ Geerling P.; de Proft, F.; Langenaeker, W. Conceptual Density Functional Theory. Chemical Reviews 2003, 103, 1793. [CrossRef]

${ }^{2}$ Sucarrat, M. T.; Salvador, P.; Sola, M.; Geerlings, P. The hardness kernel as the basis for global and local reactivity indices. Journal of Computational Chemistry 2008, 29, 1064. [CrossRef]

${ }^{3}$ Bayuelo, A. M.; Reyes, R. V. Topological model to quantify the global reactivity indexes as local in Diels-Alder reactions, using density function theory (DFT) and local quantum similarity (LQS). Journal of Mathematical Chemistry 2013, 51, 125. [CrossRef]

${ }^{4}$ Domingo, L. R.; Pérez, P. Global and local reactivity indices for electrophilic/nucleophilic free radicals. Organic \& Biomolecular Chemistry 2013, 11, 4350. [CrossRef] [PubMed]

${ }^{5}$ Parthasarathi, R.; Subramanian, V.; Chattaraj, P.K. Effect of electric field on the global and local reactivity indices, Chemical Physics Letters 2003, 382, 48. [CrossRef]

${ }^{6}$ a) Brala, C. J.; Fabijanic, I.; Markovic, A. K.; Pilepic, $V$. The average local ionization energy and Fukui function of L-ascorbate, the local reactivity descriptors of antioxidant reactivity. Computational and Theoretical Chemistry 2014, 1049, 1; [CrossRef] b)
Padmanabhan, J.; Parthasarathi, R.; Elango, M.; Subramanian, V.; Krishnamoorthy, B. S.; Gutierrez-Oliva, S.; Toro-Labbé, A.; Roy, D. R.; Chattaraj, P. K. Multiphilic Descriptor for Chemical Reactivity and Selectivity. The Journal of Physical Chemistry A 2007, 111, 9130. [CrossRef] [PubMed]

${ }^{7}$ Srivastava, S. K.; Singh V. B. Ab initio and DFT studies of the structure and vibrational spectra of anhydrous caffeine. Spectrochimica Acta Part A: Molecular and Biomolecular Spectroscopy 2013, 115, 45. [CrossRef]

${ }^{8}$ Egawa, T.; Kamiya, A.; Takeuchi, H.; Konaka, S. Molecular structure of caffeine as determined by gas electron diffraction aided by theoretical calculations. Journal of Molecular Structure 2006, 825, 151. [CrossRef]

${ }^{9}$ Latosińska, J. N.; Latosińska, M.; Olejniczak, G. A.; Seliger, J.; Zagar, V. Topology of the Interactions Pattern in Pharmaceutically Relevant Polymorphs of Methylxanthines (Caffeine, Theobromine, and Theophiline): Combined Experimental $(1 \mathrm{H}-14 \mathrm{~N}$ Nuclear Quadrupole Double Resonance) and Computational (DFT and Hirshfeld-Based) Study. Journal of Chemical Information and Modeling 2014, 54, 2570. [CrossRef]

${ }^{10}$ Poltev, V. I.; Grokhlina, T. I.; González, E.; Deriabina, A.; Cruz, A.; Gorb, L.; Leszczynski, J.; Djimant, L. N.; Veselkov A. N. Journal of Molecular Structure: THEOCHEM 2004, 709, 123. [CrossRef]

${ }^{11}$ Ucun, F.; Sağlam, A.; Güçlü, V. Molecular structures and vibrational frequencies of xanthine and its methyl derivatives (caffeine and theobromine) by ab initio Hartree-Fock and density functional theory calculations. Spectrochimica Acta Part A: Molecular and Biomolecular Spectroscopy 2007, 67, 342. [CrossRef]

${ }^{12}$ Bondesson, L.; Mikkelsen, K. V.; Luo, Y.; Garberg, P.; Agren, H. Hydrogen bonding effects on infrared and Raman spectra ofdrug molecules. Spectrochimica Acta Part A: Molecular and Biomolecular Spectroscopy 2007, 66, 213. [CrossRef]

${ }^{13}$ Mulliken, R. S. Electronic Population Analysis on LCAO-MO Molecular Wave 
Functions. The Journal of Chemical Physics 1955, 23, 1833. [CrossRef]

${ }^{14}$ Besler, B.; Merz, K.; Kollman, P. A. Atomic charges derived from semiempirical methods. Journal of Computational Chemistry 1990, 11, 431. [CrossRef]

${ }^{15}$ Löwdin, P. O. Quantum Theory of ManyParticle Systems. I. Physical Interpretations by Means of Density Matrices, Natural SpinOrbitals, and Convergence Problems in the Method of Configurational Interaction. Physical Review 1955, 97, 1474. [CrossRef]

${ }^{16}$ Kohn, W.; Beck, A. D.; Parr. R. G. The Journal of Physical Chemistry 1996, 100, 12974. [CrossRef]

${ }^{17}$ Lee, C.; Yang, W.; Parr, R. G. Development of the Colle-Salvetti correlation-energy formula into a functional of the electron density, Physical Review B 1988, 37, 785. [CrossRef]

${ }^{18}$ Miehlich, B.; Savin, A.; Stoll, H.; Preuss, H. Results obtained with the correlation energy density functionals of becke and Lee, Yang and Parr Chemical Physics Letters 1989, 157, 200. [CrossRef]

${ }^{19}$ Becke, A. D. Density-functional thermochemistry. III. The role of exact exchange. The Journal of Physical Chemistry 1993, 98, 5648. [CrossRef]

${ }^{20}$ Vydrov, O. A.; Scuseria, G. E. Assessment of a long-range corrected hybrid functional. The Journal of Physical Chemistry 2006, 125, 234109. [CrossRef]

${ }^{21}$ Vydrov, O. A.; Heyd, J.; Krukau, A.; Scuseria, G. E. Importance of short-range versus long-range Hartree-Fock exchange for the performance of hybrid density functionals. The Journal of Physical Chemistry 2006, 125, 074106. [CrossRef]

${ }^{22}$ Vydrov, O. A.; Scuseria, G. E.; Perdew, J. P. Tests of functionals for systems with fractional electron number. The Journal of Physical Chemistry 2007, 126, 154109. [CrossRef]

${ }^{23}$ Heyd, J.; Scuseria, G. E.; Ernzerhof, M. Hybrid functionals based on a screened Coulomb potential. The Journal of Physical Chemistry 2003, 118, 8207. [CrossRef]

${ }^{24}$ Heyd, J.; Scuseria, G. E. Assessment and validation of a screened Coulomb hybrid density functional. The Journal of Physical Chemistry 2004, 120, 7274. [CrossRef]

${ }^{25}$ Ernzerhof, M.; Perdew, J. P. Generalized gradient approximation to the angle- and system-averaged exchange hole. The Journal of Physical Chemistry 1998, 109, 3313. [CrossRef]

${ }^{26}$ Perdew, J. P.; Burke, K.; Ernzerhof, M. Generalized Gradient Approximation Made Simple. Physical Review Letters 1996, 77, 3865. [CrossRef]

${ }^{27}$ Frisch, M. J.; Trucks, G. W.; Schlegel, H. B.; Scuseria,G. E.; Robb, M. A.; Cheeseman, J. R.; irzewski, V. G.; Montgomery, J. A.; Jr., Stratmann, R. E.; Burant, J. C.; Dapprich, S.; Millam, J. M.; Daniels, A. D.; Kudin, K. N.; Strain, M. C.; Farkas, O.; Tomasi, J.; Barone, V.; Cossi, M.; Cammi, R.; Mennucci, B.; Pomelli, C.; Adamo, C.; Clifford, S.; Ochterski, J.; Petersson, G. A.; Ayala, P. Y.; Cui, Q.; Morokuma, K.; Malick, D. K.; Rabuck, A. D.; Raghavachari, K.; Foresman, J. B.; Cioslowski, J.; Ortiz, J. V.; Baboul, A. G.; Stefanov, B. B.; Liu, G.; Liashenko, A.; Piskorz, P.; Komaromi, I.; Gomperts, R.; Martin, R. L.; Fox, D. J.; Keith, T.; Al-Laham, M. A.; Peng, C. Y.; Nanayakkara, A.; Challacombe, M.; Gill, P. M. W.; Johnson, B.; Chen, W.; Wong, M. W.; Andres, J. L.; Gonzalez, C.; Head-Gordon, M.; Replogle, E. S.; Pople, J. A. Gaussian 98, Revision A.11.3, Gaussian, Inc., Pittsburgh, PA, 1998.

${ }^{28}$ GaussView, Version 4.1, Roy Dennington, Todd Keith, and John Millam, Semichem Inc., Shawnee Mission, KS, 2009.

${ }^{29}$ Padmaja, L.; Ravikumar, C.; Sajan, D.; Joe, I. H.; Jayakumar, V. S.; Pettit, G.R.; Nielsen, O. F. Density functional study on the structural conformations and intramolecular charge transfer from the vibrational spectra of the anticancer drug combretastatin-A2. Journal of Raman Spectroscopy 2009, 40, 419. [CrossRef]

${ }^{30}$ Ravikumar, C.; Joe, I. H.; Jayakumar, V. S. Charge transfer interactions and nonlinear optical properties of push-pull chromophore benzaldehyde phenylhydrazone: A vibrational approach. Chemical Physics Letters 2008, 460, 552. [CrossRef]

${ }^{31}$ Parr, R. G.; Pearson, R. G. Absolute hardness: companion parameter to absolute 
electronegativity. Journal of the American Chemical Society 1983, 105, 7512. [CrossRef] ${ }^{32}$ Tozer, D. J.; De Proft, F. Computation of the Hardness and the Problem of Negative Electron Affinities in Density Functional Theory. The Journal of Physical Chemistry A 2005, 109, 8923. [CrossRef]

${ }^{33}$ De Proft, F.; Sablon, N.; Tozer, D. J.; Geerlings, P. Calculation of negative electron affinity and aqueous anion hardness using Kohn-Sham HOMO and LUMO energies. Faraday Discussions 2007, 135, 151. [CrossRef]

${ }^{34}$ Iczkowski, R. P.; Margrave, J. L. E lectronegativity. Journal of the American Chemical Society 1961, 83, 3547. [CrossRef] ${ }^{35}$ Vektariene, A.; Vektaris, G.; Svoboda, J. A theoretical approach to the nucleophilic behavior of benzofused thieno[3,2-b]furans using DFT and HF based reactivity descriptors Arkivoc 2009, 311. [CrossRef]
${ }^{36}$ Zhang, G.; Musgrave, C. B. Comparison of DFT Methods for Molecular Orbital Eigenvalue Calculations. The Journal of Physical Chemistry A 2007, 111, 1554. [CrossRef]

${ }^{37}$ Lee, D.; Furche, F.; Burke, K. Accuracy of Electron Affinities of Atoms in Approximate Density Functional Theory. The Journal of Physical Chemistry Letters 2010, 2124. [CrossRef]

${ }^{38}$ Rienstra-Kiracofe, J. C.; Tschumper, G. S.; Schaefer III, H. F.; Nandi, S.; Ellison, G. B. Atomic and Molecular Electron Affinities: Photoelectron Experiments and Theoretical Computations. Chemical Reviews 2002, 102, 231. [CrossRef]

${ }^{39}$ Williams, D. E.; In Reviews of Computational Chemistry; Lipkowitz, K. B.; Boyd, D. B., eds.; 1991; Vol. II, pp. 219-271.

${ }^{40}$ Reed, A. E.; Weinstock, R. B.; Weinhold, F. Natural population analysis. The Journal of Physical Chemistry 1985, 83, 735. [CrossRef] 